\title{
Enhancement of biologically active compounds in germinated brown rice and effect of sun-drying
}

Patricio J. Cáceres ${ }^{\mathrm{a}}$, Elena Peñas ${ }^{\mathrm{b}}$, Cristina Martínez-Villaluenga ${ }^{\mathrm{b}}$, Lourdes Amigo $^{\mathrm{c}}$ and Juana Frias ${ }^{\mathrm{b}^{*}}$

${ }^{\mathrm{a} E s c u e l a ~ S u p e r i o r ~ P o l i t e ́ c n i c a ~ d e l ~ L i t o r a l, ~ C a m p u s ~ G u s t a v o ~ G a l i n d o ~ V e l a s c o, ~ k m ~ 30,5 ~}$ Vía Perimetral, Guayaquil, Ecuador

${ }^{\mathrm{b}}$ Institute of Food Science, Technology and Nutrition (ICTAN-CSIC), Juan de la Cierva 3, 28006 Madrid, Spain.

${ }^{\mathrm{C}}$ Institute of Food Science Research (CIAL) (CSIC-UAM), Nicolás Cabrera 9, Campus de Cantoblanco, 28049 Madrid, Spain

*Corresponding author: Tel.: + 34 912587510; fax: +34 915644853

E-mail address: frias@ictan.csic.es 


\begin{abstract}
Germinated brown rice (GBR) has been suggested as an approach to mitigate highly prevalent diseases providing nutrients and biologically active compounds. In this study, the content of $\gamma$-oryzanol, $\gamma$-aminobutyric acid (GABA), total phenolic compounds (TPC) and antioxidant activity of soaked BR (for $24 \mathrm{~h}$ at $28^{\circ} \mathrm{C}$ ) and GBR (for 48 and 96 $\mathrm{h}$ at $28^{\circ} \mathrm{C}$ and $34^{\circ} \mathrm{C}$ ) were determined and the effect of sun-drying as an economically affordable process was assessed. Germination improved the content of GABA, TPC and antioxidant activity in a time-dependent manner. Sun-drying increased $\gamma$-oryzanol, TPC and antioxidant activity, whereas GABA content fluctuated depending on the previous germination conditions. The main finding of this study indicates that sun-drying is an effective process promoting the accumulation of bioactive compound of GBR. Sundried GBR can be consumed as ready-to-eat food after rehydration or included in bakery products to fight non-communicable diseases.
\end{abstract}

Keywords: Brown rice, sun-drying, germination, $\gamma$-aminobutyric acid, $\gamma$-oryzanol, phenolic compounds, antioxidant activity.

\title{
1. Introduction
}

Rice (Oryza sativa L.) is one of the main cereals produced in the world and the major staple food for almost half of the world population that currently eat rice as staple food. There has been postulated a positive association between white rice intake and risk factors of CVD including metabolic syndrome and type 2 diabetes in low and 
middle-income countries (Izadi and Azadbakht, 2015). In recent years, much attention has been paid on the health benefits of brown rice (BR). BR contains health promoting compounds, including dietary fibre, $\gamma$-aminobutyric acid (GABA), vitamins, phenolic compounds and $\gamma$-oryzanol, that are mainly located in the germ and bran layers which are removed during rice polishing and milling (Monks et al., 2013).

Despite its nutritional value and beneficial physiological effects, BR is not widely consumed because it has poor cooking properties, low organoleptic quality and harsh texture (Burlando and Cornara, 2014). Numerous studies have demonstrated that germination improves texture and acceptability of BR and also enhances nutrient and phytochemical bioavailability (Komatsuzaki et al., 2005). During germination, significant changes in biochemical, nutritional and sensory characteristics occur resulting in the degradation of storage proteins and carbohydrates and promoting the synthesis and accumulation of biofunctional compounds. Germination process generally results in improved levels of vitamins, minerals, fibres and phytochemicals such as ferulic acid, GABA, $\gamma$-oryzanol and antioxidant activity (Cho and Lim, 2016).

Consumption of GBR is receiving increasing attention supported by scientific evidence on its beneficial health effects reducing the risk of diseases such as obesity (Lim et al., 2014), cardiovascular diseases (Imam et al., 2014; Mohd. Esa et al., 2011), type 2 diabetes (Imam and Ismail, 2013; Shen et al., 2015), neurodegenerative diseases (Azmi et al., 2013) and osteoporosis (Muhammad et al., 2013). In this context, GBR has been identified as a natural and inexpensive substitute of conventional white rice to improve nutritive and health status of a large world population (Wu et al., 2013).

Several studies have been carried out to optimize the germination conditions and maximize the beneficial attributes of GBR since the chemical composition of the grains change dramatically during germination (Cho and Lim, 2016). Lesser efforts, however, 
have been dedicated to evaluate the effect of drying processes to preserve the quality and composition of the obtained GBR grains. Most of the research studies focused on the production and characterization of GBR use freeze-drying, process in which water is removed by sublimation producing high-value dried products with extended shelf-life (Karam et al., 2016). This technique maintains the color, shape, aroma and nutritional quality of the product and its relevance to preserve nutraceutical compounds has been highlighted (Argyropoulos et al., 2011). However, the process is slow and requires expensive equipment and, thus, it is rarely used for the preservation of foods on the industrial scale (Vega-Mercado et al., 2001). Drying operations as convective drying, hot-air oven, vacuum, osmotic, fluidized bed and superheated steam dehydration techniques are conventionally used to achieve water evaporation in shorter times. In GBR, drying procedure system and operation conditions affect the drying rate and quality attributes, whilst starch digestibility, GABA and dietary fiber content depend on the applied temperature (Chungcharoen et al., 2014; Srisang et al., 2011). These drying methods are still expensive and not always affordable in low and middle-income countries where rice production and transformation is performed with few economic resources.

Solar drying is the oldest preservation procedure for agri-food products and it is the most common method to dehydrate rice grains in those producers' countries located in tropical areas of the world (Imoudu and Olufayo, 2000). Taking in mind its low energy cost, the aim of the present work was to evaluate for the first time the effect of sun-drying on the content of bioactive compounds in GBR. In this context, Ecuador is a tropical country which experiences little variation in daylight hours during the course of a year and temperatures oscillate between 30 and $40^{\circ} \mathrm{C}$. These climate conditions could be favourable for the stabilization of GBR by sun-drying. 
Our group has recently addressed different germination conditions to maximize the phytochemical content, antioxidant activity and nutritional features of three certified BR varieties and one experimental cultivar grown in Ecuador features (Cáceres et al., 2014a, b). In an effort to make an additional step towards sustainable and cost-effective production of Ecuadorian GBR, the present work was designed to assess the effect of different germination conditions on $\gamma$-oryzanol, GABA, total phenolic compounds and antioxidant activity in a highly produced rice variety, SLF09, and how sun-drying influence the content of those biologically active compounds. Dried GBR under sun might assure the intake of health-promoting compounds in that population where rice is the main food as ready-to-eat meals or soups after rehydration or to supplement functional foods as strategy for combating highly prevalent chronic diseases.

\section{Material and methods}

\section{1. $\quad$ Rice samples}

Commercial certified brown rice (BR) variety indica SLF09 was supplied by the company INDIA-PRONACA Co, Ecuador. This variety was selected based on its high harvest yield (6 Tm/Ha) and the consumer acceptability characterized by its translucent white center and extra-long shape grain.

\subsection{Germination process}

Fifty grams of BR were washed with distilled water and soaked in $0.1 \%$ sodium hypochloride (1:5; w/v) at $28{ }^{\circ} \mathrm{C}$ for $30 \mathrm{~min}$. After draining, BR grains were rinsed with distilled water to neutral $\mathrm{pH}$. BR grains were then soaked in distilled water $(1: 5 ; \mathrm{w} / \mathrm{v})$ at $28{ }^{\circ} \mathrm{C}$ for 24 h. Afterwards, soaking solution was removed and the soaked BR grains were obtained. 
Soaked BR were extended on drilled grilles over a moist laboratory paper and they were then covered with the same paper. The grille was placed in plastic germination trays containing distilled water in order to maintain the paper always wet by capillarity. Germination trays containing the soaked grains were introduced in a germination cabinet (model EC00-065, Snijders Scientific, Netherlands) provided with a circulating water system to keep the humidity $>90 \%$. GBR were produced at 28 and $34{ }^{\circ} \mathrm{C}$ in darkness for 48 and $96 \mathrm{~h}$. Soaked and GBR grains were dehydrated in a freezedrier (Freeze Mobile G, Virtis Company, INC Gardiner, NY, USA). Freeze-dried grains were finely ground in a ball mill (Glen Creston Ltd., Stanmore, UK), passed through a sieve of $0.5 \mathrm{~mm}$ and the obtained flour was stored under vacuum conditions in sealed plastic bags in darkness at $4{ }^{\circ} \mathrm{C}$ until further analysis. Each germination process was carried out in triplicate.

\section{3. $\quad$ Sun-drying proccess}

Fresh soaked and GBR samples produced as explained above were lied out plastic cloths under sunlight in Guayaquil (Ecuador), at a latitude of $2^{\circ} 12^{\prime} 21^{\prime}$ ' $\mathrm{S}$ and a longitude of $79^{\circ} 54^{\prime} 28^{\prime \prime}$ ' $\mathrm{W}$, an elevation of $6 \mathrm{~m}$ above the sea level with temperatures between $30-40^{\circ} \mathrm{C}$ (EXA, 2008) until GBR grains reached $\sim 10 \%$ of moisture (Imoudu and Olufayo, 2000). Sun-dried soaked and GBR were finely ground in a ball mill (Glen Creston Ltd., Stanmore, UK), passed through a sieve of $0.5 \mathrm{~mm}$ and the flour obtained was stored under vacuum conditions in sealed plastic bags in darkness at $4{ }^{\circ} \mathrm{C}$ until further analysis. Each drying process was conducted in triplicate.

\subsection{Determination of moisture content}

The content of moisture in dried soaked and GBR was determined by keeking the samples at $105^{\circ} \mathrm{C}$ to a constant weight according to AOAC 925.09 (AOAC, 2000). 


\subsection{Determination of $\gamma$-oryzanol.}

The analysis of $\gamma$-oryzanol in rice samples was performed as previously reported (Cho et al., 2012) with some modifications. Briefly, $1 \mathrm{~g}$ of sample was mixed with 10 $\mathrm{mL}$ of $100 \%$ methanol and further sonicated for $10 \mathrm{~min}$. The mixture was centrifuged at 15,000 rpm for $10 \mathrm{~min}$ at room temperature and then concentrated to dryness. Samples were then diluted in $1 \mathrm{~mL}$ of $100 \%$ methanol, filtered through a $0.45 \mu \mathrm{m}$ membrane and then analysed by HPLC. The HPLC system consisted of an Alliance Separation Module 2695 (Waters, Milford, USA), a photodiode array detector 2996 (Waters) setted at 325 nm wavelengh and Empower II software (Waters). Twenty microliters were injected onto a C18 column (150 x $3.9 \mathrm{~mm}$ i.d., $5 \mu \mathrm{m}$ size, Waters $)$. A gradient mobile phase was pumped at a flow of $1.0 \mathrm{~mL} / \mathrm{min}$ to separate the $\gamma$-oryzanol components consisting in solvent A (acetonitrile), solvent B (methanol) and solvent C (bi-distilled water) for 50 min as follows: initial isocratic flow $60 \%$ solvent $A$, $35 \%$ solvent $\mathrm{B}$ and $5 \%$ solvent $\mathrm{C}$ for 5 min, gradient flow $60 \%$ solvent $\mathrm{A}$ and $40 \%$ solvent B for 3 min keeping it at isocratic flow for 2 min, then gradient flow 22\% solvent A and $78 \%$ solvent B for 10 min, to be maintained isocratically for $15 \mathrm{~min}$, and changing to initial conditions for 10 min and, finaly, isocratic conditions to equilibrate column for $10 \mathrm{~min}$. $\gamma$-Oryzanol derivatives in rice samples were identified by retention time and spiking the sample with a commercial $\gamma$-oryzanol standard solution (Cymit, Spain) (Figure 1) and the purity of peaks was confirmed by spectra comparison and by MS analysis (Cho et al., 2012). Steryl ferulates components of $\gamma$-oryzanol were quantified by external calibration curves using $\gamma$-oryzanol standard solutions. Replicates samples were independently analyzed and results were expressed in mg $\gamma$-oryzanol/100 g of dry weight (d.w.). 


\subsection{Determination of $\gamma$-aminobutyric acid (GABA)}

$\gamma$-Aminobutyric acid (GABA) content was determined by HPLC as described previously (Cáceres et al., 2014b). Briefly, $50 \mu \mathrm{L}$ aliquot of concentrated water-soluble extract and $10 \mu \mathrm{L}$ allyl-L-glycine solution (Sigma-Aldrich) used as internal standard were derivatized with $30 \mu \mathrm{L}$ phenyl isothiocyanate (PITC 99\%, Sigma-Aldrich) and dissolved in mobile phase A for GABA analysis. An Alliance Separation Module 2695 (Waters, Milford, USA), a photodiode array detector 2996 (Waters) setted at $242 \mathrm{~nm}$ wavelenth and an Empower II chromatographic software (Waters) were used as chromatographic system. A volume of $20 \mu \mathrm{L}$ of sample were injected onto a C18 Alltima 250 x $4.6 \mathrm{~mm}$ i.d., $5 \mu \mathrm{m}$ size (Alltech, Spain) column thermostatted at $30{ }^{\circ} \mathrm{C}$. The chromatogram was developed at a flow rate of $1.0 \mathrm{~mL} / \mathrm{min}$ by eluting the sample with mobile phase A (0.1 M ammonium acetate $\mathrm{pH}$ 6.5) and mobile phase $\mathrm{B}(0.1 \mathrm{M}$ ammonium acetate, acetonitrile, methanol, 44/46/10, v/v/v, pH 6.5). Replicates samples were independently analyzed and results were expressed as mg GABA/100 g d.w.

\subsection{Determination of total phenolic content}

The Folin-Ciocalteu's method was used for the quantification of total phenolic content (TPC), as previously reported (Cáceres et al., 2014b). The absorbance was measured at $739 \mathrm{~nm}$ using a microplate reader (Synergy HT, BioTek Instruments) and TPC were quantified by external calibration using gallic acid (Sigma-Aldrich) as standard. Sample replicates were independently analyzed and results were expressed as mg of gallic acid equivalents (GAE)/100 g d.w.

\subsection{Determination of antioxidant activity}

Antioxidant activity was determined by the method of oxygen radical absorbance capacity (ORAC) by fluorescence detection ( $\lambda_{\text {exc }} 485 \mathrm{~nm}$ and $\lambda_{\text {em }} 520 \mathrm{~nm}$ ) using an automatic plate reader (BioTek Instruments), previously described (Cáceres et al., 
2014b). Sample replicates were independently analyzed and results were expressed as mg of Trolox equivalents (TE)/100g of sample d.w.

\subsection{Statistical analysis}

Each germination experiment and subsequent drying process were conducted in triplicate. Two extractions were performed for each replicate and the analytical determinations were carried out in triplicate. Data were expressed as mean \pm standard deviation. The data obtained from each experimental condition were subjected to oneway analysis of variance (ANOVA) using Duncan test to determine the significant differences at $\mathrm{P} \leq 0.05$ level using Statgraphics Centurion XVI Program, version 16.1.17 (Statistical Graphics Corporation, Rockville, Md) for Windows. This programme was also used for correlation analysis.

\section{Results}

In order to study the effect of germination on biologically active compounds of $\mathrm{BR}$, soaked and GBR were freeze-dried as this drying process minimize its degradation and deterioration In parallel, fresh soaked and GBR were dried under the sun and the moisture content ranged between 9.5-12.5

\subsection{Effect of germination on $\gamma$-oryzanol content in brown rice variety SLF09}

BR variety SLF09 exhibited four main chromatographic peaks that unambiguously were identified as cycloartenyl ferulate (peak 1), 24-methylene cycloartanyl ferulate (peak 2), campestryl ferulate (peak 3) and sitosteryl ferulate (peak 4) (Figure 1), confirmed by spicking with commercial standard $\gamma$-oryzanol by HPLC and mass espectrometry analysis. The quantitative results revealed that 24-methylene cycloartanyl ferulate (peak 2) was present in the larger amount (4.98 mg/100g d.w.), 
followed by cycloartenyl ferulate (peak 1) and campestryl ferulate (peak 3) (2.6 and $2.24 \mathrm{mg} / 100 \mathrm{~g}$ d.w., respectively) and, finally, sitosteryl ferulate (peak 4) (1.34 mg/100g d.w.), accounting for a total amount of $11.17 \mathrm{mg} \gamma$-oryzanol/100g d.w. (Table 1). Total content of $\gamma$-oryzanol underwent a significantly decrease $(\mathrm{P} \leq 0.05)$ during the initial soaking treatment (from 11.17 to $9.23 \mathrm{mg} / 100 \mathrm{~g}$ d.w.) and a $17 \%$ reduction was observed. This effect was due to drops exhibited by the individual derivatives: Campestryl ferulate suffered the largest decrease (25\%), followed by sitosteryl ferulate (20\%) and, in less amount, cycloartenyl and 24-methylene cycloartanyl ferulates (15\%) (Table 1). Germination process did not bring about further $\gamma$-oryzanol losses, since most of the steryl derivative concentrations kept almost unchanged $(P \geq 0.05)$, and concentrations ranged from 9.2 to $9.64 \mathrm{mg} / 100 \mathrm{~g}$ d.w. in GBR grains (Table 1).

In an attempt to stablish the proportion of each individual derivative within the total $\gamma$-oryzanol content before and after germination, the contribution of each steryl ferulate to the total $\gamma$-oryzanol content was calculated (Figure 2). In crude BR, 24methylene cycloartanyl ferulate was the predominant one (45\%), followed by cycloartenyl ferulate (23\%), then campestryl ferulate (20\%) and, finaly, sitosteryl ferulate (12\%). These proportions were mainteined almost invaried after soaking and slight modifications were appreciated in GBR samples. While the contributions of cycloartenyl and sitosteryl ferulates did not change during germination, those for 24methylene cycloartanyl and campestryl ferulates were modified to aproximately 48 and 17\%, respectively (Figure 2).

\subsection{Effect of germination on GABA content in brown rice variety SLF09}

Table 2 reports the GABA content in ungerminated, soaked and GBR. Variety SLF09 showed a concentration of $1.07 \mathrm{mg}$ GABA/100g d.w. that increased 7-fold after 
soaking process carried out at $28{ }^{\circ} \mathrm{C}$ for $24 \mathrm{~h}$. During germination, a gradual and timedependent accumulation of GABA was achieved and $28{ }^{\circ} \mathrm{C}$ produced larger amounts of this compound (34.8 mg/100 g d.w. and $99 \mathrm{mg} / 100 \mathrm{~g}$ d.w. for 48 and 96 h, respectively) than $34{ }^{\circ} \mathrm{C}$ (24.3 mg/100g d.w and $83.6 \mathrm{mg} / 100 \mathrm{~g} \mathrm{d.w.} \mathrm{for} 48$ and $96 \mathrm{~h}$, respectively).

3.3. Effect of germination on the content of total phenolic compounds in brown rice variety SLF09

Changes in total phenolic compounds (TPC) of BR at different germination conditions are presented in Table 2. The TPC in crude samples corresponded to 132.53 mg GAE/100g d.w. and this content underwent a significantly $(\mathrm{P} \leq 0.05)$ decrease after steeping process (113.23 mg GAE/100g d.w.). Germination, however, led to a sharp increment in the concentration of these compounds with time, reaching values of 187.17 and $176.48 \mathrm{mg}$ GAE/100g d.w. for 48h-GBR and of 298.23 and $382.99 \mathrm{mg}$ GAE/100g d.w. for $96 h-G B R$, at 28 and $34^{\circ} \mathrm{C}$, respectively.

\subsection{Effect of germination on the antioxidant activity in brown rice variety SLF09}

The total antioxidant activity of crude, soaked and GBR grains determined by the ORAC-FL method is also collected in Table 2. The antioxidant activity of nongerminated SLF09 grains was $494.81 \mathrm{mg}$ TE/100g d.w. and soaking did not cause significant $(\mathrm{P} \geq 0.05)$ changes. During germination process, the antioxidant activity increased gradually following a time-dependent pattern and higher temperature led to higher levels. Thus 48h-GBR samples exhibited 554.85 and $662.8 \mathrm{mg}$ TE/100g d.w. at 28 and $34{ }^{\circ} \mathrm{C}$, respectively, whilst 96h-GBR grains showed larger activity (977.47 and 1079.35 mg TE/100g d.w. for those respective temperatures). However, there was not 
found a significant correlation between antioxidant activity and $\gamma$-oryzanol content of GBR (freeze-dried) samples (Figure 6C).

3.5. Effect of sun-drying on the content of $\gamma$-oryzanol, GABA, TPC and antioxidant activity of germinated brown rice variety SLF09

Tables 1 and 2 include the content of $\gamma$-oryzanol, GABA, TPC and antioxidant activity in sundried soaked and GBR. This drying process increased the content of $\gamma$ oryzanol in GBR from $14.1 \mathrm{mg} / 100 \mathrm{~g}$ d.w. in soaked and $28{ }^{\circ} \mathrm{C} / 48 \mathrm{~h}-\mathrm{GBR}$ samples to $18.2 \mathrm{mg} / 100 \mathrm{~g}$ d.w. in $28{ }^{\circ} \mathrm{C} / 96 \mathrm{~h}-\mathrm{GBR}$ ones, representing a 34 and $48 \%$ increment, respectively. Sundried $34{ }^{\circ} \mathrm{C} / 48 \mathrm{~h}-\mathrm{GBR}$ and $34{ }^{\circ} \mathrm{C} / 96 \mathrm{~h}-\mathrm{GBR}$ showed $\gamma$-oryzanol concentrations of $16.7 \mathrm{mg} / 100 \mathrm{~g}$ d.w., accounting for an increment of $42 \%$ (Figure 3). These amounts are the result of the accumulation of the individual steryl ferulates during sun-drying that reached values in the range of $2.6-3.56 \mathrm{mg} / 100 \mathrm{~g}$ d.w. for cycloartenyl ferulate, $6.07-7.7 \mathrm{mg} / 100 \mathrm{~g}$ d.w. for 24-methylene cycloartanyl ferulate, 3.56-4.64 mg/100g d.w. for campestryl ferulate and 1.78- $2.30 \mathrm{mg} / 100 \mathrm{~g}$ d.w. for sitosteryl ferulate (Table 1). Figure 2 illustrates the contributions of individual steryl ferulates to the total $\gamma$-oryzanol content. Sun-drying increased the proportion of campestryl ferulate to approximately 25-26\%, whilst cycloartenyl ferulate and 24methylene cycloartanyl ferulate decreased to $18-19 \%$ and $42-43 \%$, respectively, whilst sitosteryl ferulate was not modified.

The content of GABA in sundried GBR grains is found in Table 2. The largest GABA accumulation was achieved for those samples previously germinated for $96 \mathrm{~h}$ (49.8 and $66.4 \mathrm{mg} / 100 \mathrm{~g} \mathrm{d.w}$. at 28 and $34{ }^{\circ} \mathrm{C}$, respectively), whilst temperature did not modified GABA content in GBR for $48 \mathrm{~h}(\sim 36.5 \mathrm{mg} / 100 \mathrm{~g}$ d.w.) and soaked BR provided the lowest GABA content. Sun-drying only increased GABA content in 
soaked and $34{ }^{\circ} \mathrm{C} / 48 \mathrm{~h}$ GBR (41 and 33\%, respectively), did not cause significant GABA modification in $28{ }^{\circ} \mathrm{C} / 48 \mathrm{~h}$ GBR, while for those BR grains germinated for $96 \mathrm{~h}$, sundrying led to unexpected GABA losses (99 and $24 \%$ at 28 and $34^{\circ} \mathrm{C}$, respectively) (Figure 3).

Sun-drying brought about slight changes in TPC content of GBR and only in those germinated for $96 \mathrm{~h}$, sun-drying led to significant $(\mathrm{P} \leq 0.05)$ enhancement of TPC (Table 2, Figure 3). However, the antioxidant activity underwent a gradual and significant $(\mathrm{P} \leq 0.05)$ increase in sundried GBR that was higher for those GBR produced at $28{ }^{\circ} \mathrm{C}$ (978.6 and $1283.25 \mathrm{mg}$ TE/100 g d.w. for 48 and $96 \mathrm{~h}$, respectively), althought those germinated at $34{ }^{\circ} \mathrm{C}$ also provided a large ORAC value (826.8 and $1174.9 \mathrm{mg} \mathrm{TE} / 100 \mathrm{~g}$ d.w. for 48 and $96 \mathrm{~h}$, respectively). In all the samples, sun-drying caused a sharp increment in antioxidant activity compared with the GBR counterparts (Figure 3).

In an attempt to elucidate the potential compounds responsible for antioxidant activity, Figure 4shows the correlation between ORAC values and TPC and $\gamma$-oryzanol content in GBR and sundried GBR. A significant positive correlation $(\mathrm{P} \leq 0.05)$ was found between ORAC and $\gamma$-oryzanol (Figure 4A) (r=0.82) and TPC (Figure 4B) $(\mathrm{r}=0.86)$ of sundried GBR, and between antioxidant activity and TPC content of GBR (Figure 4D) (r=0.96).

\section{Discussion}

BR variety SLF09 is largely produced in Eduador by INDIA-PRONACA and exported to other Latin American countries. It is one of the long grain rice indica varieties highly consumed due to this varity of rice remains loose after cooking. In Ecuador, this rice is produced at local farmlands that currently reach overproduction (Cáceres et al., 2014a), mainly used for animal feeding and, hence, undervaluaded. 
Therefore, germination of BR emerges as a simple cost-effective strategy for enhancing the content of bioactive compounds. In addition, economic, effective and sustainable sun-drying provided by Ecuadorian climatology provided moisture content lower than $15 \%$, in acordance to Imoudu and Olufayo (2000), contributing to the preservation of GBR for further storage, comercialization and consumption as ready-to-eat staple food or to be incorporated in demanded functional foods with added-value (Cornejo et al., 2015). In this context, GBR can contribute to reduce the risk of cardiometabolic diseases in those populations where rice constitute the main energy and nutrient food without altering the existing consumption habits (Ochoa-Avilés et al., 2014).

The composition of GBR depends on many factors such as genotype diversity, soaking conditions, germination time and temperature, as well as drying process. It is well known that germination process generally improves the nutritional quality, by augmenting the protein digestibility, vitamins, minerals and inducing the formation of bioactive components (Cho and Lim, 2016).

In our study, BR variery SLF09 provides $\gamma$-oryzanol in the form of four main derivatives. A wide range of variation for total $\gamma$-oryzanol has been reported previously in varieties of BR from different geographical origin (Cho et al., 2012; Khatoon and Gopalakrishna, 2004; Kiing et al., 2009; Miller and Engel, 2006; Ohtsubo et al., 2005; Pereira-Caro et al., 2013). Values ranging from $1.2 \mathrm{mg} / 100 \mathrm{~g}$ in BR varieties from the Camargue region of France (Pereira-Caro et al., 2013) to $313 \mathrm{mg} / 100 \mathrm{~g}$ in a BR cultivar cultivated in Taiwan (Huang and Ng, 2012) have been reported. The amounts of $\gamma$ oryzanol found in BR variety SLF09 is comparable to those previously reported in three indica cultivars grown in Brazil (Pascual et al., 2013), and in eight cultivars from South Sarawak, Malaysia (Kiing et al., 2009). The contribution of each steryl ferulate to total $\gamma$-oryzanol content lies within the range previously reported in different French rice 
varieties (Pereira-Caro et al., 2013) and differ to those observed in long BR grain cultivars (Miller and Engel, 2006), in which the largest proportion was accounted by cycloartenyl ferulate (43-48\%), followed by 24-methylene cycloartanyl ferulate (2629\%) and, in minor proportions, campestryl ferulate (17-21\%) and sitosteryl ferulate (78\%). The different proportions of individual $\gamma$-oryzanol constituents have been attributed to the variability among genotypes.

During germination process, $\gamma$-oryzanol underwent a significant decrease (15\%) that occurred mainly during the initial hydration process and not further changes during germination were found. Results from the literature about the effect of germination on the content of total $\gamma$-oryzanol in BR are not coincident possibly due to the different germination conditions used. Our results are in accordance with those previously reported in several BR cultivars from Malaysia (Kiing et al., 2009) where a decrease of $\gamma$-oryzanol after germination at $25^{\circ} \mathrm{C}$ for $24 \mathrm{~h}$ was observed, and differ to Thai cultivar RD-6 that underwent an increase after 12 h-soaking and further 24 h-germination at 28$30{ }^{\circ} \mathrm{C}$ (Moongngarm and Saetung, 2010), or to those Indian varieties IR 64 and BPT that did not show changes in $\gamma$-oryzanol content after $16 \mathrm{~h}$ of soaking followed by120 $\mathrm{h}$ of germination at room temperature (Jayadeep and Malleshi, 2011). During the germination process hydrolytic enzymes are activated and the effect observed on $\gamma$ oryzanol could be due to the induction of feruloyl esterases activity during the initial soaking process (Sancho et al., 1999). In addition, steryl ferulate degradation was also attributed to dynamic ferulic acid metabolism during BR hydration (Tian et al., 2004). Nevertheless, our results indicate that individual steryl ferulate contribution remained almost constant throughtout germination process showing that these compounds seems to be stable after $96 \mathrm{~h}$ at 28 and $34^{\circ} \mathrm{C}$, effect that has not been reported previously. 
GBR were sundried and $\gamma$-oryzanol increased between 34 and $48 \%$, results reported for the first time in this work. These outcomes evidence the accumulation of $\gamma$ oryzanol derivatives during drying under solar exposition that can be attributed to the sunlight effect on ferulic acid metabolism and further synthesis of individual $\gamma$-oryzanol components. It has been reported that sunlight has a profound effect on the biosynthesis of ferulic acid esters by affecting the metabolic activation of enzymes involved in the defence mechanism to radiation (Wang et al., 2014), and also in the development of new plant structural tissues (Hoson and Wakabayashi, 2015). To our knowledge, this is the first report describing the effect of sun-drying on $\gamma$-oryzanol content and composition evidencing GBR as a rich source of $\gamma$-oryzanol.

It is widely recognized that $\gamma$-oryzanol and its individual components are natural antioxidant. Among them, 24-methylene cycloartenyl ferulate exhibited the greatest antioxidant potential (Xu et al., 2001) and, together with cycloartenyl ferulate, showed anti-inflammatory properties (Akihisa et al., 2000). In addition, $\gamma$-oryzanol has shown anti-atherogenic, anti-cholesterolemic, hypolipidemic and anti-cancer effects in vivo (Wilson et al., 2007). $\gamma$-Oryzanol is administrated to the treatment of diabetes, menopause, allergies and gastrointestinal inflammatory diseases (Lemus et al., 2014). These properties make $\gamma$-oryzanol one of the most demanding compounds for nutraceutical, pharmaceutical and cosmeceutical preparations (Ghatak and Panchal, 2011). Our results show that sun-drying may improveeven more $\gamma$-oryzanol content in GBR, and can be considered as a sustainable bio-efficient process to develop $\gamma$-oryzanol enriched GBR.

GABA is usually present as a minor compound in crude grains, however, germination boosts its accumulation in rice sprouts (Cáceres et al., 2014b; Ohtsubo et al., 2005). GABA synthesis is usually initiated as consequence of the activation of 
glutamate decarboxylase (GAD) enzyme during soaking process, activity that increases with germination time whilst temperature seems to exert a minor impact (Cáceres et al., 2014b; Roohinejad et al., 2011). GAD catalyses the decarboxylation of glutamic acid to GABA and $\mathrm{CO}_{2}$ and it has been established a range between 20 and $40{ }^{\circ} \mathrm{C}$ as optimal temperature for enzyme activity (Yang et al., 2013). Additionally, GABA can also be synthetized from putrescine as a response to abiotic stress during germination (Shelp et al., 2012) contributing to the overall account of GABA in GBR. Our results are consistent with those published recently for GBR, with values ranging from 34.5 to 140 mg GABA/100g d.w. (Cáceres et al., 2014b; Hayat et al., 2015; Roohinejad et al., 2011; Yang et al., 2013; Zhang et al., 2014).

The drying process of GBR under sunlight had a different effect on GABA depending on germination conditions and higher amounts were only found in soaked BR and $34{ }^{\circ} \mathrm{C} / 48 \mathrm{~h} \mathrm{GBR}$. These results can be partly attributable to some remaining GAD activity after germination due to the activity of this enzyme at temperatures below $40{ }^{\circ} \mathrm{C}$ (Kim et al., 2014). GABA diminution was observed in those dried samples previously germinated for $96 \mathrm{~h}$, results that could be attributed to sunlight exposure activation of GABA shunt pathway. These metabolic pathway uses GABA as precursor for the synthesis of succinic acid required in the Krebs cycle (Fait et al., 2008). Nevertheless, the content of GABA in sundried GBR has been described for the first time in the present work, ranging from $12 \mathrm{mg} / 100 \mathrm{~g}$ in soaked grains to $67 \mathrm{mg} / 100 \mathrm{~g}$ in $34{ }^{\circ} \mathrm{C} / 96 \mathrm{~h}$ GBR. GABA has a well-known antihypertensive and it has been reported that a daily GABA intake of 20 mg caused a reduction of blood pressure in individuals with pre-hypertension (Inoue et al., 2003). Furthermore, a daily dose of $26.4 \mathrm{mg}$ of GABA seems to be effective in the treatment of neurological disorders (Diana et al., 2014). 
Taking into account that $100 \mathrm{~g}$ of sun-dried GBR provide between 1.5 to 3-fold these required amounts, its consumption would provide health beneficial effects.

BR is considered a good source of phenolic compounds and the content in the variety SLF09 is within the range previously reported (Ti et al., 2014). TPC content increased sharply as consequence of germination time while temperature had a minor influence (Cáceres et al., 2014b). This increment was partially explained by the production of enzymes that hydrolyse fiber components during GBR germination (Tian et al., 2004). In addition, the action of endogenous esterases can release free phenolics required for the synthesis of more complex compounds (Hatfield et al., 1999) providing, at the same time, defence against environmental agents (Lemus et al., 2014). Moreover, germination induces the expression of phenylalanine ammonia-lyase producing cinnamic acid from phenylanine which is, then, metabolized into other free phenolic acids (Shih et al., 2008). GBR obtained at $34^{\circ} \mathrm{C}$ for $96 \mathrm{~h}$ in the present work exhibited greater TPC content than those reported previously (Cáceres et al., 2014b; Moongngarm and Saetung, 2010; Ti et al., 2014). Ti et al., (2014) identified protocatechuic, chorogenic, caffeic and ferulic acids as the main phenolic acids and the later was the most abundant (357 $\mu \mathrm{g} / \mathrm{g}$ d.w. after 5 day-germination).

Sun-drying kept or, even, increased the content of TPC (Figure 3) although a drop due to their susceptibility to oxidation during light exposure should be expected. TPC increase after sun-drying of GBR could be explained by activation of the phenylpropanoid pathway that occur in response to environmental factors (Reilly et al., 2014; Shih et al., 2008) and increased exposure to UV-B light (Du et al., 2014). To our knowledge, we present here inedited results describing the sun-drying effect on the content of TPC of GBR that provide 176 to $383 \mathrm{mg}$ GAE/100g d.w. depending on previous germination conditions. Phenolic compounds are considered bioactive 
compounds with health implications (Roleira et al., 2015). Particularly, ferulic acid bound to dietary fiber plays an important role in the prevention of colon cancer and attenuates inflammation (Shao and Bao, 2015). Moreover, soluble phenolic acids inhibit the oxidation of LDL cholesterol and the cell membrane liposomes enhancing mental health, immunity and protecting against diabetes deterioration (Chandrasekara and Shahidi, 2011). Therefore, sundried GBR can be considered an important source of phenolic compounds with beneficial attributes.

The antioxidant activity found in BR was higher than those observed in different Ecuadorian BR (Cáceres et al., 2014b), ranging between 242.7 and 316.8 mg TE/100g d.w., and differ to those reported by (Ti et al., 2014), who found levels of $38.7 \mu$ mol TE/g in BR variety Tianyou 998. This variability on antioxidant activity in crude grains could be attributed to the phenolic composition in different BR genotypes as well as to the contribution of other antioxidant compounds such as $\gamma$-oryzanol and vitamin $\mathrm{E}$ isomers (Cáceres et al., 2014b; Moongngarm and Saetung, 2010). Germination enhanced the antioxidant potential of BR variety SLF09, in agreement with previous studies (Cáceres et al., 2014b; Ti et al., 2014; Tian et al., 2004). During germination of BR, antioxidant activity was time and temperature dependent, as recently reported (Cáceres et al., 2014b), most likely caused by the accumulation of compounds with peroxyl-scavenging activity such as phenolic compounds (Andriantsitohaina et al., 2012; Zhou et al., 2014), as it was confirmed by the positive correlation obtained between antioxidant activity and TPC (Figure 4D). In addition, it has been suggested that soluble phenolic compounds account for $30 \%$ of the antioxidant activity (Adom and Liu, 2002). Nevertheless, $\gamma$-oryzanol can also contribute to the overall antioxidant activity (Aguilar-Garcia et al., 2007), however, in the present study, positive correlation between them in GBR was not found (Figure 4C). Other antioxidant compounds such as 
tocopherols, tocotrienols, phytates and vitamin C could also contribute to this biological activity (Fardet, 2010; Frias et al., 2005). In sundried GBR samples, antioxidant activity was always significantly $(\mathrm{P} \leq 0.05)$ higher than their germinated counterparts, phenomenon that can be attributed to the increase observed in bioactive compounds such as $\gamma$-oryzanol and polyphenols. This hypothesis was confirmed by the positive correlations found between them (Figure 4A and 4B, respectively). Recent research shows that antioxidant activity of GBR is associated with the prevention of oxidative stress-related diseases (Lemus et al., 2014). It has been reported that GBR increases antioxidant enzyme activity and reduces lipid peroxidation in hypercholesterolimic rabbits (Mohd. Esa et al., 2011). To our knowledge, this is the first study showing antioxidant activity of sun-dried GBR and its consumption could contribute to ameliorate oxidative stress-induced diseases.

\section{Conclusions}

Germination conditions modify the content of biologically active compounds of BR variety SLF09. $\gamma$-Oryzanol decreased slightly during germination and sun-drying led to an important accumulation. GABA was synthetized during germination in a timedependent manner and underwent significant rises after sun-drying only in those germinated for $48 \mathrm{~h}$. TPC and antioxidant activity increased during germination that were preserved or even enhanced under solar dehydration. These outcomes show germination as a simple and sustainable process to preserve BR bioactive compounds and reveal, for the first time, the effectiveness of sun-drying for maximizing their accumulation. The obtained sun-dried GBR can be consumed directly after rehydatation as staple food or, after a milling process, can be incorporated in bakery products and pasta (Cornejo et al., 2015). In this context, consumption of sundried GBR can take 
place as parbolished rice to feed children and adolescents contributing to the control of metabolic related disorders (Ochoa-Avilés et al., 2012).

\section{Acknowledgments}

This work has received financial support from the project AGL2013-43247R from Ministerio de Economia y Competitividad (Spain) and European Union through FEDER Programme. P. J. Caceres is indebted to the Ministry of High Education, Science, Technology and Innovation (SENESCYT, Ecuador) for the foreign Ph.D. grant and E.Peñas to Ramon y Cajal Programme for financial support. We also acknowledge to INDIA-PRONACA enterprise for providing the BR cultivars.

\section{References}

Adom, K.K., Liu, R.H. (2002). Antioxidant activity of grains. Journal of Agricultural and Food Chemistry, 50(21), 6182-6187.

Aguilar-Garcia, C., Gavino, G., Baragaño-Mosqueda, M., Hevia, P., Gavino, V.C. (2007). Correlation of tocopherol, tocotrienol, $\gamma$-oryzanol and total polyphenol content in rice bran with different antioxidant capacity assays. Food Chemistry, 102(4), 1228-1232.

Akihisa, T., Yasukawa, K., Yamaura, M., Ukiya, M., Kimura, Y., Shimizu, N., Arai, K., (2000). Triterpene alcohol and sterol ferulates from rice bran and their antiinflammatory effects. Journal of Agricultural and Food Chemistry, 48(6), 23132319.

Andriantsitohaina, R., Auger, C., Chataigneau, T., Étienne-Selloum, N., Li, H., Martínez, M.C., Schini-Kerth, V.B., Laher, I., (2012). Molecular mechanisms of 
the cardiovascular protective effects of polyphenols. British Journal of Nutrition, 108(9), 1532-1549.

AOAC, 2000 Official Methods of Analysis of the Association of Official Analytical Chemists. 17th Edition.

Argyropoulos, D., Heindl, A., Müller, J., (2011). Assessment of convection, hot-air combined with microwave-vacuum and freeze-drying methods for mushrooms with regard to product quality. International Journal of Food Science and Technology, 46(2), 333-342.

Azmi, N.H., Ismail, N., Imam, M.U., Ismail, M., (2013). Ethyl acetate extract of germinated brown rice attenuates hydrogen peroxide-induced oxidative stress in human SH-SY5Y neuroblastoma cells: Role of anti-apoptotic, pro-survival and antioxidant genes. BMC Complementary and Alternative Medicine, 13:177. DOI: 10.1186/1472-6882-13-177.

Burlando, B., Cornara, L., (2014). Therapeutic properties of rice constituents and derivatives (Oryza sativa L.): A review update. Trends in Food Science and Technology. DOI: 10.1016/j.tifs.2014.08.002.

Cáceres, P.J., Martínez-Villaluenga, C., Amigo, L., Frias, J., (2014a). Assessment on Proximate Composition, Dietary Fiber, Phytic Acid and Protein Hydrolysis of Germinated Ecuatorian Brown Rice. Plant Foods for Human Nutrition, 69(3) 261267.

Cáceres, P.J., Martínez-Villaluenga, C., Amigo, L., Frias, J., (2014b). Maximising the phytochemical content and antioxidant activity of Ecuadorian brown rice sprouts through optimal germination conditions. Food Chemistry, 152, 407-414. 
Cornejo, F., Caceres, P.J., Martínez-Villaluenga, C., Rosell, C.M., Frias, J., (2015). Effects of germination on the nutritive value and bioactive compounds of brown rice breads. Food Chemistry, 173, 298-304.

Chandrasekara, A., Shahidi, F., (2011). Bioactivities and antiradical properties of millet grains and hulls. Journal of Agricultural and Food Chemistry 59(17), 9563-9571.

Cho, D.H., Lim, S.T., (2016). Germinated brown rice and its bio-functional compounds. Food Chemistry, 196, 259-271.

Cho, J.Y., Lee, H.J., Kim, G.A., Kim, G.D., Lee, Y.S., Shin, S.C., Park, K.H., Moon, J.H., (2012). Quantitative analyses of individual $\gamma$-Oryzanol (Steryl Ferulates) in conventional and organic brown rice (Oryza sativa L.). Journal of Cereal Science, 55(3), 337-343.

Chungcharoen, T., Prachayawarakorn, S., Tungtrakul, P., Soponronnarit, S., (2014). Effects of germination process and drying temperature on gamma-aminobutyric acid (GABA) and starch digestibility of germinated brown rice. Drying Technology, 32(6), 742-753.

Diana, M., Quílez, J., Rafecas, M., (2014). Gamma-aminobutyric acid as a bioactive compound in foods: A review. Journal of Functional Foods, 10, 407-420.

Du, W.X., Avena-Bustillos, R.J., Breksa, A.P., McHugh, T.H., (2014). UV-B light as a factor affecting total soluble phenolic contents of various whole and fresh-cut specialty crops. Postharvest Biology and Technology, 93, 72-82.

EXA, A.E.C.E., (2008). El informe Hiperión, p. 50.

Fait, A., Fromm, H., Walter, D., Galili, G., Fernie, A.R., (2008). Highway or byway: the metabolic role of the GABA shunt in plants. Trends in Plant Science, 13(1), 1419. 
Fardet, A., (2010). New hypotheses for the health-protective mechanisms of wholegrain cereals: What is beyond fibre? Nutrition Research Reviews, 23(1), 65-134.

Frias, J., Miranda, M.L., Doblado, R., Vidal-Valverde, C., (2005). Effect of germination and fermentation on the antioxidant vitamin content and antioxidant capacity of Lupinus albus L. var. Multolupa. Food Chemistry, 92(2), 211-220.

Ghatak, S.B., Panchal, S.J., (2011). Gamma-oryzanol - A multi-purpose steryl ferulate. Current Nutrition and Food Science, 7(1), 10-20.

Hatfield, R.D., Ralph, J., Grabber, J.H., (1999). Cell wall cross-linking by ferulates and diferulates in grasses. Journal of the Science of Food and Agriculture, 79(3), 403407.

Hayat, A., Jahangir, T.M., Khuhawar, M.Y., Alamgir, M., Hussain, Z., Haq, F.U., Musharraf, S.G., (2015). HPLC determination of gamma amino butyric acid (GABA) and some biogenic amines (BAs) in controlled, germinated, and fermented brown rice by pre-column derivatization. Journal of Cereal Science, 64, 56-62.

Hoson, T., Wakabayashi, K., (2015). Role of the plant cell wall in gravity resistance. Phytochemistry, 112(1), 84-90.

Huang, S.H., Ng, L.T., (2012). Quantification of polyphenolic content and bioactive constituents of some commercial rice varieties in Taiwan. Journal of Food Composition and Analysis, 26(1-2), 122-127.

Imam, M.U., Ishaka, A., Ooi, D.J., Zamri, N.D.M., Sarega, N., Ismail, M., Esa, N.M., (2014). Germinated brown rice regulates hepatic cholesterol metabolism and cardiovascular disease risk in hypercholesterolaemic rats. Journal of Functional Foods, 8(1), 193-203. 
Imam, M.U., Ismail, M., (2013). Nutrigenomic effects of germinated brown rice and its bioactives on hepatic gluconeogenic genes in type 2 diabetic rats and HEPG2 cells. Molecular Nutrition and Food Research 57(3), 401-411.

Imoudu, P.B., Olufayo, A.A., (2000). The effect of sun-drying on milling yield and quality of rice. Bioresource Technology 74(3), 267-269.

Inoue, K., Shirai, T., Ochiai, H., Kasao, M., Hayakawa, K., Kimura, M., Sansawa, H., (2003). Blood-pressure-lowering effect of a novel fermented milk containing $\gamma$ aminobutyric acid (GABA) in mild hypertensives. European Journal of Clinical Nutrition, 57(3), 490-495.

Izadi, V., Azadbakht, L. (2015). Is there any association between rice consumption and some of the cardiovascular diseases risk factors? A systematic review. Advanced Research Yields in Atherosclerosis, 11(1), 109-115.

Jayadeep, A., Malleshi, N.G., (2011). Nutrients, composition of tocotrienols, tocopherols, and c-oryzanol, and antioxidant activity in brown rice before and after biotransformation. CYTA - Journal of Food, 9(1), 82-87.

Karam, M.C., Petit, J., Zimmer, D., Baudelaire Djantou, E., Scher, J., (2016). Effects of drying and grinding in production of fruit and vegetable powders: A review. Journal of Food Engineering, 188, 32-49.

Khatoon, S., Gopalakrishna, A.G., (2004). Fat-soluble nutraceuticals and fatty acid composition of selected indian rice varieties. JAOCS, Journal of the American Oil Chemists' Society, 81(10), 939-943.

Kiing, S.C., Yiu, P.H., Rajan, A., Wong, S.C., (2009). Effect of germination on $\gamma-$ oryzanol content of selected sarawak rice cultivars. American Journal of Applied Sciences, 6(9), 1658-1661. 
Kim, H.S., Lee, E.J., Lim, S.T., Han, J.A., (2014). Self-enhancement of GABA in rice bran using various stress treatments. Food Chemistry, 172, 657-662.

Komatsuzaki, N., Shima, J., Kawamoto, S., Momose, H., Kimura, T., (2005). Production of $\gamma$-aminobutyric acid (GABA) by Lactobacillus paracasei isolated from traditional fermented foods. Food Microbiology, 22(6), 497-504.

Lamberts, L., Joye, I.J., Beliën, T., Delcour, J.A., (2012). Dynamics of $\gamma$-aminobutyric acid in wheat flour bread making. Food Chemistry, 130(4), 896-901.

Lemus, C., Angelis, A., Halabalaki, M., Skaltsounis, A.L., (2014). $\gamma$-Oryzanol. An Attractive Bioactive Component from Rice Bran, Wheat and Rice in Disease Prevention and Health, pp. 409-430.

Lim, S.M., Goh, Y.M., Kuan, W.B., Loh, S.P., (2014). Effect of germinated brown rice extracts on pancreatic lipase, adipogenesis and lipolysis in 3T3-L1 adipocytes. Lipids in Health and Disease, 13, 169. DOI: 10.1186/1476-511X-13-169.

Miller, A., Engel, K.H., (2006). Content of $\gamma$-oryzanol and composition of steryl ferulates in brown rice (Oryza sativa L.) of European origin. Journal of Agricultural and Food Chemistry, 54(21), 8127-8133.

Mohd. Esa, N., Abdul Kadir, K.K., Amom, Z., Azlan, A., (2011). Improving the lipid profile in hypercholesterolemia-induced rabbit by supplementation of germinated brown rice. Journal of Agricultural and Food Chemistry, 59(14), 7985-7991.

Monks, J.L.F., Vanier, N.L., Casaril, J., Berto, R.M., de Oliveira, M., Gomes, C.B., de Carvalho, M.P., Dias, A.R.G., Elias, M.C., (2013). Effects of milling on proximate composition, folic acid, fatty acids and technological properties of rice. Journal of Food Composition and Analysis, 30(2), 73-79. 
Moongngarm, A., Saetung, N., (2010). Comparison of chemical compositions and bioactive compounds of germinated rough rice and brown rice. Food Chemistry, 122(3), 782-788.

Muhammad, S.I., Ismail, M., Mahmud, R.B., Salisu, A.M., Zakaria, Z.A., (2013). Germinated brown rice and its bioactives modulate the activity of uterine cells in oophorectomised rats as evidenced by gross cytohistological and immunohistochemical changes. BMC Complementary and Alternative Medicine, 13, 198. DOI: 10.1186/1472-6882-13-198.

Ochoa-Avilés, A., Andrade, S., Huynh, T., Verstraeten, R., Lachat, C., Rojas, R., Donoso, S., Manuel-Y-Keenoy, B., Kolsteren, P., (2012). Prevalence and socioeconomic differences of risk factors of cardiovascular disease in Ecuadorian adolescents. Pediatric Obesity, 7(4), 274-283.

Ochoa-Avilés, A., Verstraeten, R., Lachat, C., Andrade, S., Van Camp, J., Donoso, S., Kolsteren, P., (2014). Dietary intake practices associated with cardiovascular risk in urban and rural Ecuadorian adolescents: A cross-sectional study. BMC Public Health, 14(1), 939. DOI: 10.1186/1471-2458-14-939

Ohtsubo, K., Suzuki, K., Yasui, Y., Kasumi, T., (2005). Bio-functional components in the processed pre-germinated brown rice by a twin-screw extruder. Journal of Food Composition and Analysis, 18(4), 303-316.

Pascual, C.S.C.I., Massaretto, I.L., Kawassaki, F., Barros, R.M.C., Noldin, J.A., Marquez, U.M.L., (2013). Effects of parboiling, storage and cooking on the levels of tocopherols, tocotrienols and $\gamma$-oryzanol in brown rice (Oryza sativa L.). Food Research International, 50(2), 676-681. 
Pereira-Caro, G., Cros, G., Yokota, T., Crozier, A., (2013). Phytochemical profiles of black, red, brown, and white rice from the camargue region of France. Journal of Agricultural and Food Chemistry, 61(33), 7976-7986.

Reilly, K., Valverde, J., Finn, L., Rai, D.K., Brunton, N., Sorensen, J.C., Sorensen, H., Gaffney, M., (2014). Potential of cultivar and crop management to affect phytochemical content in winter-grown sprouting broccoli (Brassica oleracea L. var. italica). Journal of the Science of Food and Agriculture, 94(2), 322-330.

Roleira, F.M.F., Tavares-Da-Silva, E.J., Varela, C.L., Costa, S.C., Silva, T., Garrido, J., Borges, F., (2015). Plant derived and dietary phenolic antioxidants: Anticancer properties. Food Chemistry, 183, 235-258.

Roohinejad, S., Omidizadeh, A., Mirhosseini, H., Saari, N., Mustafa, S., Meor Hussin, A.S., Hamid, A., Abd Manap, M.Y., (2011). Effect of pre-germination time on amino acid profile and gamma amino butyric acid (GABA) contents in different varieties of Malaysian brown rice. International Journal of Food Properties, 14(6), 1386-1399.

Sancho, A.I., Faulds, C.B., Bartolomé, B., Williamson, G., (1999). Characterisation of feruloyl esterase activity in barley. Journal of the Science of Food and Agriculture, 79(3), 447-449.

Shao, Y., Bao, J., (2015). Polyphenols in whole rice grain: Genetic diversity and health benefits. Food Chemistry, 180, 86-97.

Shelp, B.J., Bozzo, G.G., Trobacher, C.P., Zarei, A., Deyman, K.L., Brikis, C.J., (2012). Hypothesis/review: Contribution of putrescine to 4-aminobutyrate (GABA) production in response to abiotic stress. Plant Science, 193-194, 130-135.

Shen, K.P., Hao, C.L., Yen, H.W., Chen, C.Y., Wu, B.N., Lin, H.L., (2015). Pregerminated brown rice prevents high-fat diet induced hyperglycemia through 
elevated insulin secretion and glucose metabolism pathway in C57BL/6J strain mice. Journal of Clinical Biochemistry and Nutrition, 56(1), 28-34.

Shih, C.H., Chu, H., Tang, L.K., Sakamoto, W., Maekawa, M., Chu, I.K., Wang, M., Lo, C., (2008). Functional characterization of key structural genes in rice flavonoid biosynthesis. Planta, 228(6), 1043-1054.

Srisang, N., Varanyanond, W., Soponronnarit, S., Prachayawarakorn, S., (2011). Effects of heating media and operating conditions on drying kinetics and quality of germinated brown rice. Journal of Food Engineering, 107(3-4), 385-392.

Strumłło, C., Adamiec, J., (1996). Energy and quality aspects of food drying. Drying Technology, 14(2), 423-448.

Ti, H., Zhang, R., Zhang, M., Li, Q., Wei, Z., Zhang, Y., Tang, X., Deng, Y., Liu, L., Ma, Y., (2014). Dynamic changes in the free and bound phenolic compounds and antioxidant activity of brown rice at different germination stages. Food Chemistry, 161, 337-344.

Tian, S., Nakamura, K., Kayahara, H., (2004). Analysis of phenolic compounds in white rice, brown rice, and germinated brown rice. Journal of Agricultural and Food Chemistry, 52(15), 4808-4813.

Vega-Mercado, H., Marcela Góngora-Nieto, M., Barbosa-Cánovas, G.V., (2001). Advances in dehydration of foods. Journal of Food Engineering, 49(4), 271-289.

Wang, W., Guo, J., Zhang, J., Peng, J., Liu, T., Xin, Z., (2014). Isolation, identification and antioxidant activity of bound phenolic compounds present in rice bran. Food Chemistry, 171, 40-49.

Wilson, T.A., Nicolosi, R.J., Woolfrey, B., Kritchevsky, D., (2007). Rice bran oil and oryzanol reduce plasma lipid and lipoprotein cholesterol concentrations and aortic cholesterol ester accumulation to a greater extent than ferulic acid in 
hypercholesterolemic hamsters. Journal of Nutritional Biochemistry, 18(2), 105112.

Wu, F., Chen, H., Yang, N., Duan, X., Jin, Z., Xu, X., (2013). Germinated brown rice enhances antioxidant activities and immune functions in aged mice. Cereal Chemistry, 90(6), 601-607.

Xu, Z., Hua, N., Samuel Godber, J., (2001). Antioxidant activity of tocopherols, tocotrienols, and $\gamma$-oryzanol components from rice bran against cholesterol oxidation accelerated by 2,2'-azobis(2-methylpropionamidine) dihydrochloride. Journal of Agricultural and Food Chemistry, 49(4), 2077-2081.

Yang, R., Yin, Y., Guo, Q., Gu, Z., (2013). Purification, properties and cDNA cloning of glutamate decarboxylase in germinated faba bean (Vicia faba L.). Food Chemistry, 138(2-3), 1945-1951.

Zhang, Q., Xiang, J., Zhang, L., Zhu, X., Evers, J., van der Werf, W., Duan, L., (2014). Optimizing soaking and germination conditions to improve gamma-aminobutyric acid content in japonica and indica germinated brown rice. Journal of Functional Foods, 10, 283-291.

Zhou, Z., Chen, X., Zhang, M., Blanchard, C., (2014). Phenolics, flavonoids, proanthocyanidin and antioxidant activity of brown rice with different pericarp colors following storage. Journal of Stored Products Research, 59, 120-125. 
Table 1. Content of $\gamma$-oryzanol components (mg/100g dw) in crude, soaked and germinated brown rice variety SFL09 and the effect of sun-drying.

\begin{tabular}{|c|c|c|c|c|c|}
\hline BR samples & $\begin{array}{l}\text { Cycloartenyl } \\
\text { ferulate } \\
\text { (Peak 1) }\end{array}$ & $\begin{array}{l}\text { 24-Methylene } \\
\text { cycloartanyl ferulate } \\
\text { (Peak 2) }\end{array}$ & $\begin{array}{l}\text { Campestryl ferulate } \\
\text { (Peak 3) }\end{array}$ & $\begin{array}{l}\text { Sitosteryl } \\
\text { ferulate } \\
\text { (Peak 4) }\end{array}$ & $\begin{array}{l}\text { Total } \gamma \text { - } \\
\text { oryzanol }\end{array}$ \\
\hline Crude & $2.60 \pm 0.05^{\mathrm{b}}$ & $4.98 \pm 0.07^{\mathrm{d}}$ & $2.24 \pm 0.03^{\mathrm{bA}}$ & $1.34 \pm 0.02^{b}$ & $11.17 \pm 0.10^{\mathrm{b}}$ \\
\hline \multicolumn{6}{|l|}{ Freeze-dried } \\
\hline $\begin{array}{l}\text { Soaked } \\
28^{\circ} \mathrm{C}, 24 \mathrm{~h}\end{array}$ & $2.21 \pm 0.04^{\mathrm{a}}$ & $4.27 \pm 0.06^{\mathrm{aA}}$ & $1.67 \pm 0.05^{\mathrm{aA}}$ & $1.08 \pm 0.02^{\mathrm{aA}}$ & $9.23 \pm 0.08^{\mathrm{aA}}$ \\
\hline \multicolumn{6}{|l|}{ Germinated } \\
\hline $28^{\circ} \mathrm{C}, 48 \mathrm{~h}$ & $2.22 \pm 0.06^{\mathrm{aA}}$ & $4.32 \pm 0.12^{\mathrm{abA}}$ & $1.61 \pm 0.05^{\mathrm{aA}}$ & $1.05 \pm 0.03^{\mathrm{aA}}$ & $9.20 \pm 0.20^{\mathrm{aA}}$ \\
\hline $28^{\circ} \mathrm{C}, 96 \mathrm{~h}$ & $2.32 \pm 0.07^{\mathrm{aA}}$ & $4.52 \pm 0.10^{\mathrm{bcA}}$ & $1.58 \pm 0.03^{\mathrm{aA}}$ & $1.09 \pm 0.02^{\mathrm{aA}}$ & $9.52 \pm 0.17^{\mathrm{aA}}$ \\
\hline $34^{\circ} \mathrm{C}, 48 \mathrm{~h}$ & $2.33 \pm 0.13^{\mathrm{aA}}$ & $4.56 \pm 0.20^{\mathrm{cA}}$ & $1.59 \pm 0.15^{\mathrm{aA}}$ & $1.11 \pm 0.08^{\mathrm{aA}}$ & $9.59 \pm 0.56^{\mathrm{aA}}$ \\
\hline $34^{\circ} \mathrm{C}, 96 \mathrm{~h}$ & $2.36 \pm 0.11^{\mathrm{aA}}$ & $4.58 \pm 0.19^{\mathrm{cA}}$ & $1.60 \pm 0.09^{\mathrm{aA}}$ & $1.10 \pm 0.05^{\mathrm{aA}}$ & $9.64 \pm 0.42^{\mathrm{aA}}$ \\
\hline \multicolumn{6}{|l|}{ Sun-dried } \\
\hline $\begin{array}{l}\text { Soaked } \\
28^{\circ} \mathrm{C}, 24 \mathrm{~h}\end{array}$ & $2.63 \pm 0.11^{b}$ & $6.07 \pm 0.18^{\mathrm{eB}}$ & $3.56 \pm 0.13^{\mathrm{cB}}$ & $1.82 \pm 0.03^{\mathrm{bB}}$ & $14.08 \pm 0.19^{\mathrm{bB}}$ \\
\hline \multicolumn{6}{|l|}{ Germinated } \\
\hline $28^{\circ} \mathrm{C}, 48 \mathrm{~h}$ & $2.60 \pm 0.05^{\mathrm{bB}}$ & $6.08 \pm 0.17^{\mathrm{eB}}$ & $3.65 \pm 0.09^{\mathrm{cB}}$ & $1.78 \pm 0.03^{\mathrm{bB}}$ & $14.09 \pm 0.21^{\mathrm{bB}}$ \\
\hline $28^{\circ} \mathrm{C}, 96 \mathrm{~h}$ & $3.56 \pm 0.05^{\mathrm{cB}}$ & $7.70 \pm 0.09^{\mathrm{fB}}$ & $4.64 \pm 0.09^{\mathrm{eB}}$ & $2.30 \pm 0.03^{\mathrm{cB}}$ & $18.18 \pm 0.17^{\mathrm{dB}}$ \\
\hline $34^{\circ} \mathrm{C}, 48 \mathrm{~h}$ & $3.24 \pm 0.06^{\mathrm{cB}}$ & $7.23 \pm 0.04^{\mathrm{fB}}$ & $4.15 \pm 0.04^{\mathrm{dB}}$ & $2.11 \pm 0.01^{\mathrm{cB}}$ & $16.75 \pm 0.09^{\mathrm{cB}}$ \\
\hline $34^{\circ} \mathrm{C}, 96 \mathrm{~h}$ & $3.09 \pm 0.12^{\mathrm{cB}}$ & $7.21 \pm 0.11^{\mathrm{fB}}$ & $4.36 \pm 0.15^{\mathrm{eB}}$ & $2.07 \pm 0.02^{\mathrm{cB}}$ & $16.73 \pm 0.07^{\mathrm{cB}}$ \\
\hline
\end{tabular}

Data are the mean values \pm standard deviation of three independent experiments $(n=3)$. Lowercase letters indicate statistical differences among germination conditions ( $\mathrm{P} \leq 0.05$ according to Duncan's test). Uppercase letters indicate statistical differences among drying process for a same germination conditions ( $\mathrm{P} \leq 0.05$ according to Duncan’s test). 
Table 2. Content of $\gamma$-aminobutyric acid (GABA), total phenolic compounds (TPC) and antioxidant activity (ORAC) of crude, soaked and germinated brown rice and the effect of sundrying.

\begin{tabular}{llll}
\hline BR samples & $\begin{array}{l}\text { GABA } \\
(\mathrm{mg} / 100 \mathrm{~g})\end{array}$ & $\begin{array}{l}\text { TPC } \\
(\mathrm{mg} \mathrm{GAE} / 100 \mathrm{~g} \mathrm{dm})\end{array}$ & $\begin{array}{l}\text { ORAC } \\
(\mathrm{mg} \mathrm{TE} / 100 \mathrm{~g} \mathrm{dm})\end{array}$ \\
\hline Crude & $1.07 \pm 0.09^{\mathrm{a}}$ & $132.53 \pm 2.78^{\mathrm{b}}$ & $494.81 \pm 19.71^{\mathrm{a}}$
\end{tabular}

Freeze-dried

\begin{tabular}{llll}
\hline $\begin{array}{l}\text { Soaked } \\
28^{\circ} \mathrm{C}, \text { 24h }\end{array}$ & $7.46 \pm 0.12^{\mathrm{bA}}$ & $113.23 \pm 7.77^{\mathrm{aA}}$ & $508.41 \pm 12.49^{\mathrm{abA}}$ \\
Germinated & & & \\
$28^{\circ} \mathrm{C}, 48 \mathrm{~h}$ & $34.84 \pm 2.78^{\mathrm{dA}}$ & $187.17 \pm 3.19^{\mathrm{dA}}$ & $554.85 \pm 17.59^{\mathrm{bA}}$ \\
$28^{\circ} \mathrm{C}, 96 \mathrm{~h}$ & $99.03 \pm 4.83^{\mathrm{fA}}$ & $298.23 \pm 13.48^{\mathrm{eA}}$ & $977.47 \pm 62.49^{\mathrm{dA}}$ \\
$34^{\circ} \mathrm{C}, 48 \mathrm{~h}$ & $24.33 \pm 0.44^{\mathrm{cA}}$ & $176.48 \pm 3.02^{\mathrm{cA}}$ & $622.80 \pm 18.60^{\mathrm{cA}}$ \\
$34^{\circ} \mathrm{C}, 96 \mathrm{~h}$ & $83.60 \pm 2.67^{\mathrm{eA}}$ & $382.99 \pm 10.44^{\mathrm{gA}}$ & $1079.35 \pm 69.70^{\mathrm{dA}}$ \\
& & & \\
Sun-dried & & & \\
\hline & & & $547.66 \pm 25.22^{\mathrm{eA}}$ \\
Soaked & $12.75 \pm 0.50^{\mathrm{gB}}$ & $118.14 \pm 5.30^{\mathrm{fA}}$ & \\
$28^{\circ} \mathrm{C}, 24 \mathrm{~h}$ & & & $978.63 \pm 30.33^{\mathrm{fB}}$ \\
Germinated & & & $1283.25 \pm 74.04^{\mathrm{iB}}$ \\
$28^{\circ} \mathrm{C}, 48 \mathrm{~h}$ & $36.41 \pm 2.67^{\mathrm{hA}}$ & $190.29 \pm 8.55^{\mathrm{gA}}$ & $826.82 \pm 54.82^{\mathrm{gB}}$ \\
$28^{\circ} \mathrm{C}, 96 \mathrm{~h}$ & $49.85 \pm 4.62^{\mathrm{iB}}$ & $359.22 \pm 12.35^{\mathrm{hB}}$ & $1174.88 \pm 45.48^{\mathrm{hA}}$ \\
\hline $34^{\circ} \mathrm{C}, 48 \mathrm{~h}$ & $36.50 \pm 1.36^{\mathrm{hB}}$ & $195.13 \pm 18.26^{\mathrm{gA}}$ & \\
$34^{\circ} \mathrm{C}, 96 \mathrm{~h}$ & $66.94 \pm 1.21^{\mathrm{jB}}$ & $429.34 \pm 17.54^{\mathrm{iB}}$ & \\
\hline
\end{tabular}

Data are the mean values \pm standard deviation of three independent experiments $(n=3)$. Lowercase letters indicate statistical differences among germination conditions ( $\mathrm{P} \leq 0.05$ according to Duncan's test). Uppercase letters indicate statistical differences among drying process for a same germination conditions ( $\mathrm{P} \leq 0.05$ according to Duncan's test). 
Peak 2

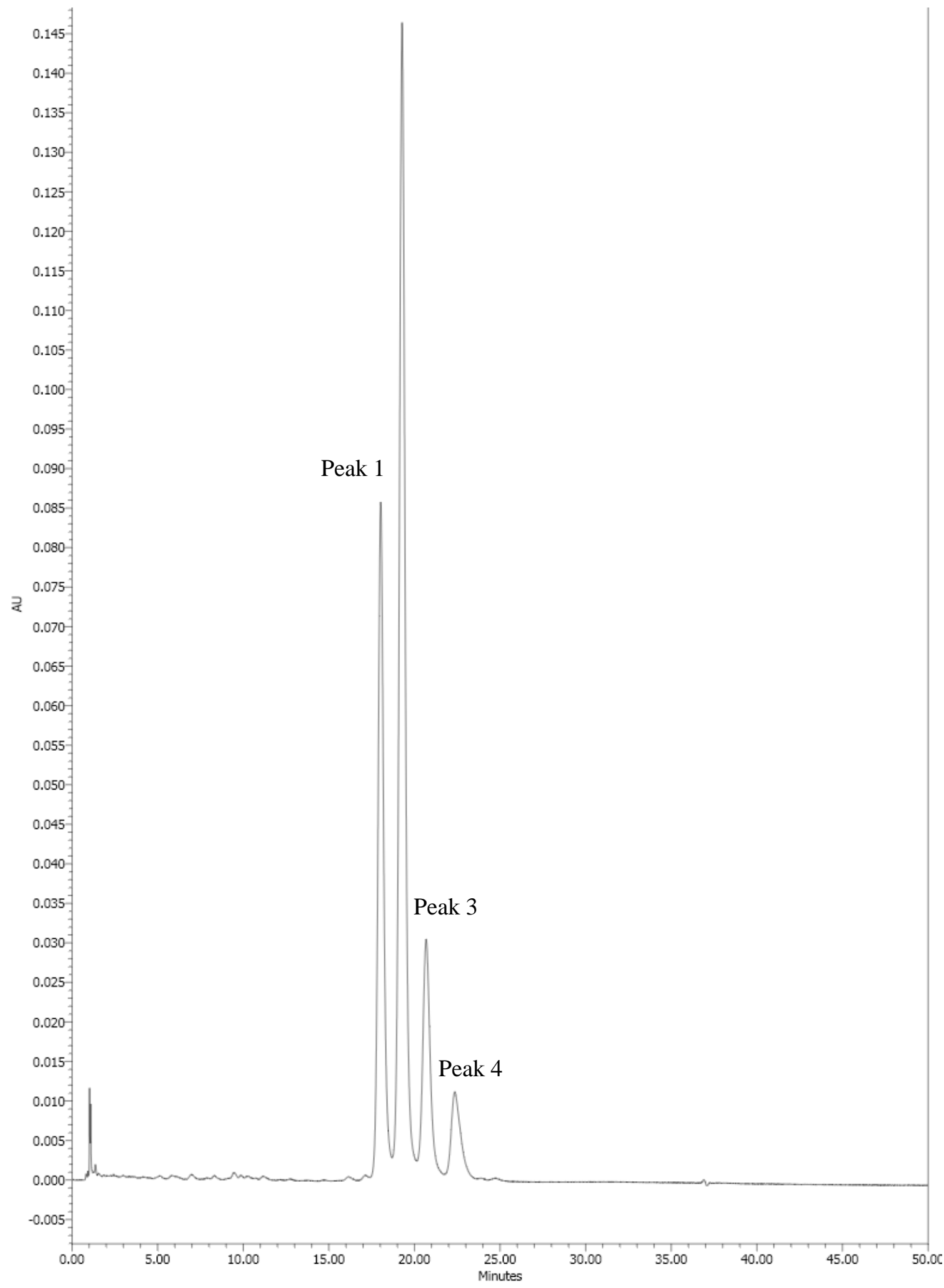

Figure 1. Chromatogram of $\gamma$-oryzanol standard. Peak 1, cycloartenyl ferulate; peak 2, 24methylenecycloartanyl ferulate; peak 3, campesteryl ferulate; peak 4, sitosteryl ferulate. 


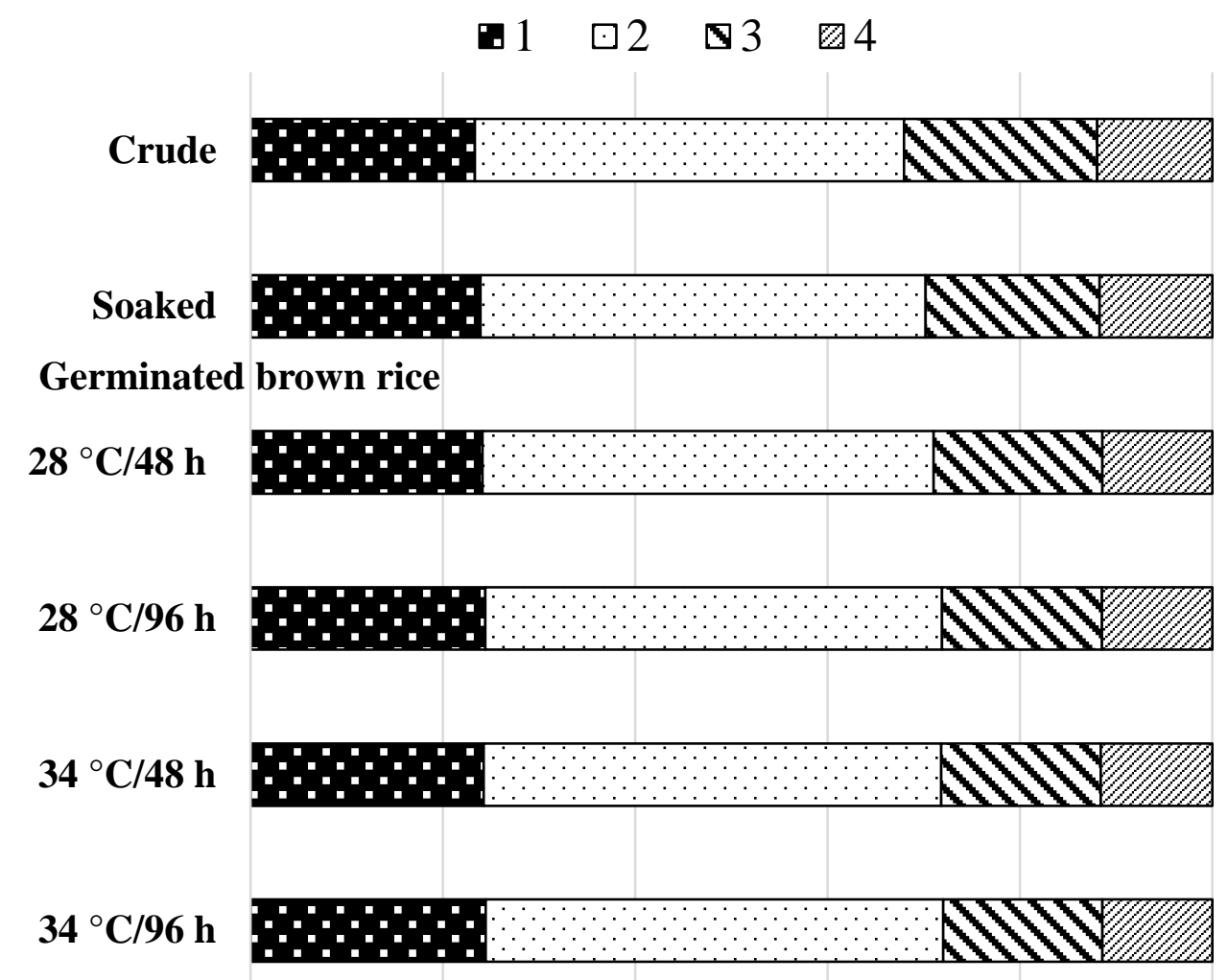

\section{Sun-Dried}

Soaked

Germinated brown rice

$28{ }^{\circ} \mathrm{C} / 48 \mathrm{~h}$

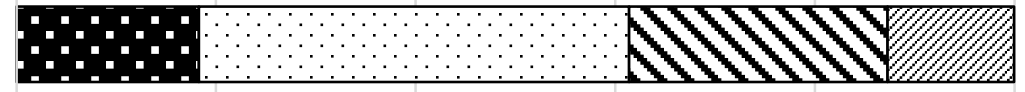

$28{ }^{\circ} \mathrm{C} / 96 \mathrm{~h}$

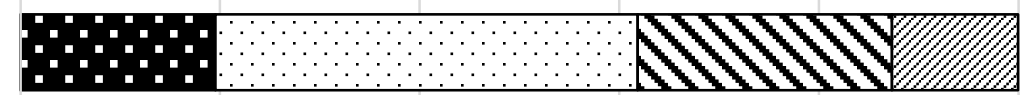

$34{ }^{\circ} \mathrm{C} / 48 \mathrm{~h}$

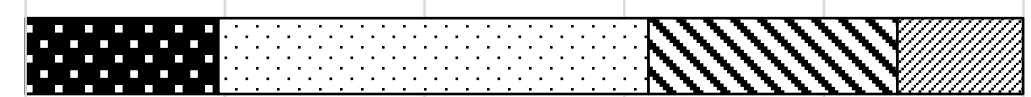

$34{ }^{\circ} \mathrm{C} / 96 \mathrm{~h}$

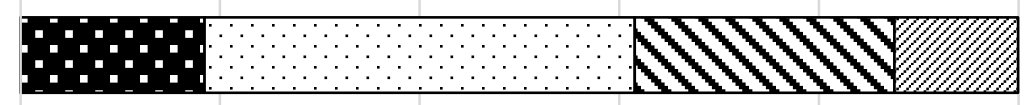

$\begin{array}{llllll}0 \% & 20 \% & 40 \% & 60 \% & 80 \% & 100 \%\end{array}$

Figure 2. Contribution of the individual steryl ferulates to total content of $\gamma$-oryzanol in crude, soaked, and germinated brown rice and effect of sun-drying. 1, cycloartenyl ferulate; 2, 24-methylenecycloartanyl ferulate; 3, campesteryl ferulate; 4, sitosteryl ferulate. 


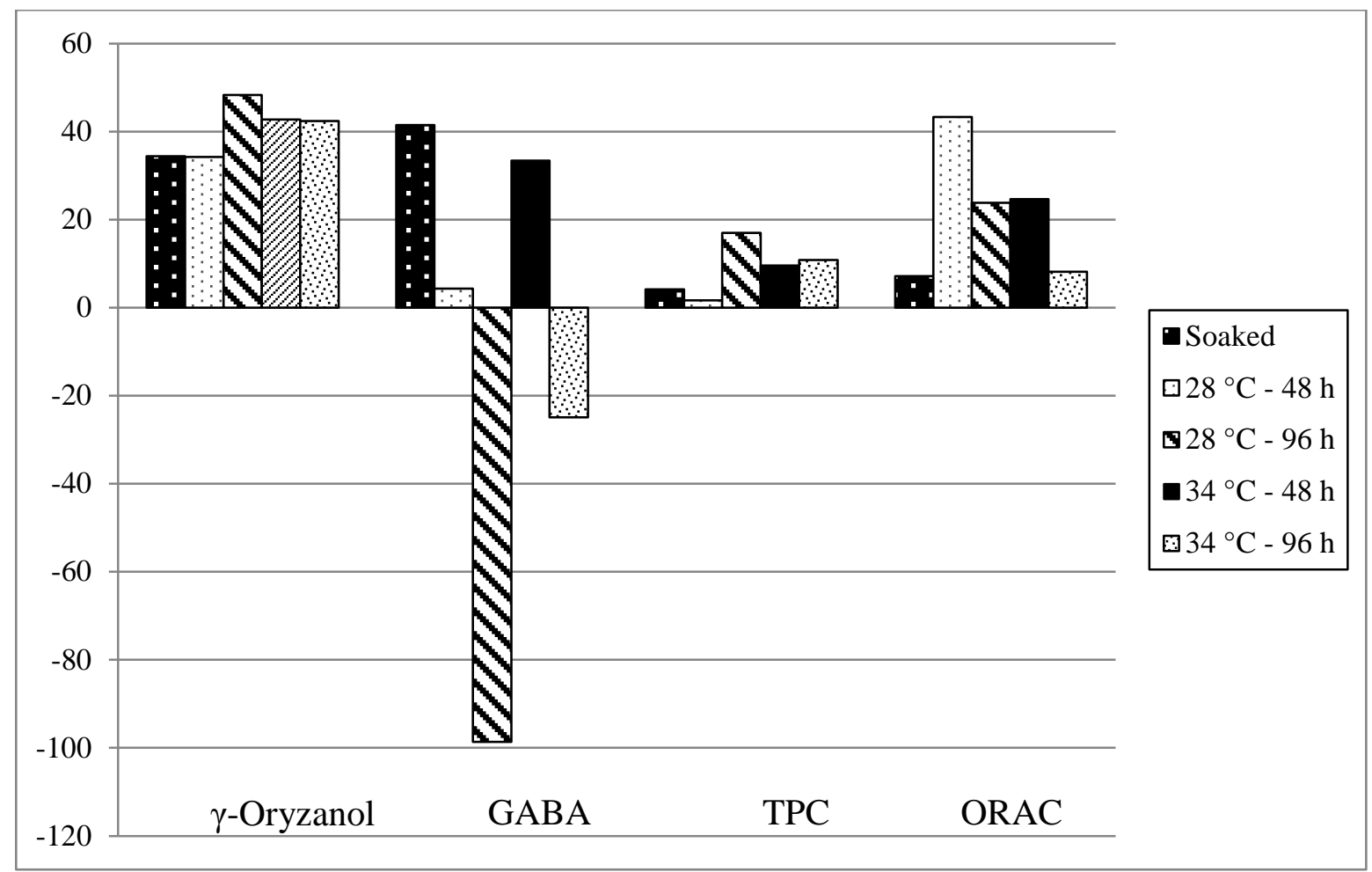

Figure 3. Effect of sun-drying on bioactive compounds and antioxidant activity of soaked and germinated brown rice, indicating increase percentages (positive y-axe) or decrease percentages (negative y-axe). 

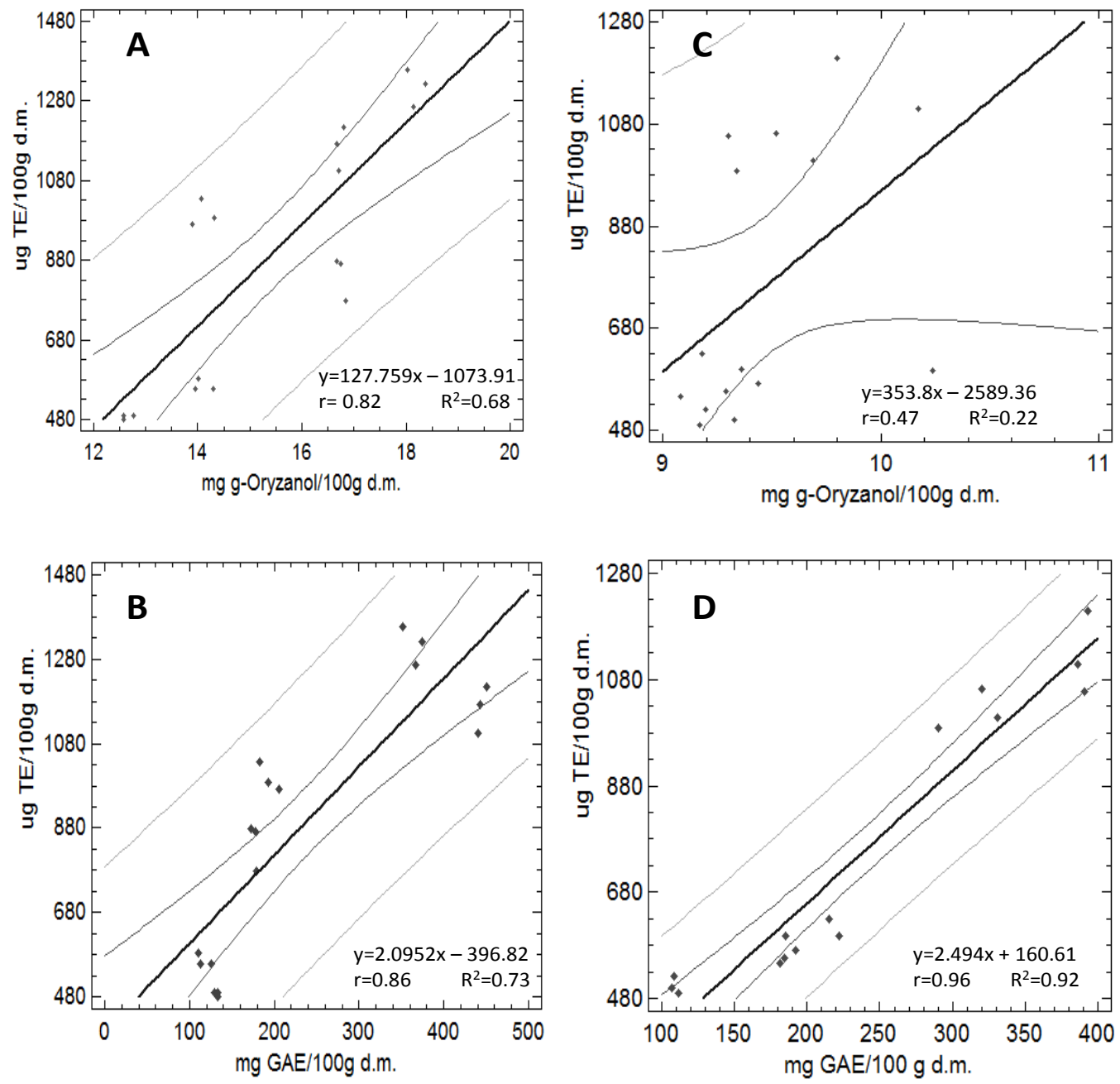

Figure 4. Antioxidant activity correlated (r) with the content of $\gamma$-oryzanol (A) and TPC (B) of SD-BR germinated and with the content of $\gamma$-oryzanol (C) and TPC (D) of FD-BR germinated. $\mathrm{R}^{2}$ indicates the percentage of variation explained by the model. 